\title{
Selective Modification of Short-Term Hippocampal Synaptic Plasticity and Impaired Memory Extinction in Mice with a Congenitally Reduced Hippocampal Commissure
}

\author{
Lesley A. Schimanski, ${ }^{1}$ Douglas Wahlsten, ${ }^{3,4}$ and Peter V. Nguyen ${ }^{1,2,3}$ \\ Departments of ${ }^{1}$ Physiology and ${ }^{2}$ Psychiatry and ${ }^{3}$ Centre for Neuroscience, University of Alberta School of Medicine, \\ Edmonton, Alberta T6G 2H7, Canada, and 4Department of Psychology, Faculty of Science, University of Alberta, \\ Edmonton, Alberta T6G 2E9, Canada
}

The hippocampus is critical for forming new long-term memories, but the contributions of the hippocampal commissure $(\mathrm{HC})$ to memory function and hippocampal synaptic plasticity are unclear. To shed light on this issue, we characterized behavioral memory and hippocampal synaptic plasticity in two inbred mouse strains. BALB/cWah1 mice display a range of corpus callosal defects and an intact HC, whereas 9XCA/Wah mice exhibit a complete absence of corpus callosum and a greatly reduced $\mathrm{HC}$. No differences between strains were found in long-term potentiation (LTP) within two synaptic pathways in hippocampal slices. However, paired-pulse facilitation was deficient in area CA1 of slices from 9XCA/Wah, and it was rescued by decreasing extracellular $\left[\mathrm{Ca}^{2+}\right]$, suggesting that presynaptic calcium dynamics may be altered in this strain. In addition, contextual fear extinction was impaired in 9XCA/Wah mice, but performance on cued fear extinction and on $24 \mathrm{hr}$ memory tests for cued and contextual fear conditioning were not significantly different between strains. Thus, an intact $\mathrm{HC}$ is critical for normal extinction of contextual fear. Intact interhemispheric connectivity is not required for acquisition or expression of cued and contextual fear conditioning. LTP was normal in slices from mice that lacked an intact $\mathrm{HC}$, and this was correlated with normal performance on fear conditioning tests. In contrast, impaired short-term synaptic plasticity was correlated with defective contextual memory extinction in mice lacking an intact $\mathrm{HC}$. Thus, the $\mathrm{HC}$ in mice is vital for particular aspects of memory function and for short-term synaptic modification in specific hippocampal circuits.

Key words: hippocampal commissure; memory; learning; LTP; fear conditioning; extinction; agenesis; mouse strains; synaptic plasticity
The classic case study of H.M., a patient with surgical transection of the medial temporal lobes, demonstrated that the hippocampus is critical for the formation of new declarative memories (Scoville and Milner, 1957). Studies of human commissurotomy patients indicate that the main interhemispheric communication pathway between hippocampi, the hippocampal commissure (HC), is important for normal memory function. Indeed, patients with a transected $\mathrm{HC}$ show greater recognition memory deficits than those with an intact HC (Phelps et al., 1991). Patients with transection of both the corpus callosum (CC) and the HC also showed poor memory performance (Zaidel and Sperry, 1974). These findings indicate that an intact $\mathrm{CC}$ and $\mathrm{HC}$ are required for normal memory function.

In two common inbred mouse strains, BALB/c and 129, agenesis of the $\mathrm{CC}$ occurs in $<50 \%$ of these mice, whereas the remainder appear to have normal forebrain commissures (see Fig.

\footnotetext{
Received May 7, 2002; revised June 14, 2002; accepted June 25, 2002.

This work was supported by grants and funds from the Natural Sciences and Engineering Research Council of Canada (NSERC) (D.W., P.V.N.) and from the Alberta Heritage Foundation for Medical Research (AHFMR), the Medical Research Council of Canada (MRC), and the Canadian Neurotrauma Research Program (Alberta Paraplegic Foundation) (P.V.N.). L.A.S. is supported by an NSERC Postgraduate Scholarship A Studentship. P.V.N. is a Scholar of the AHFMR and MRC. We thank Sean Cooper for the staining and analysis of brain tissue and Dr. Mark Barad from the University of California, Los Angeles for technical advice on extinction.

Correspondence should be addressed to Dr. Peter Nguyen, Department of Physiology, University of Alberta, Medical Sciences Building, Edmonton, Alberta, T6G 2H7, Canada. E-mail: peter.nguyen@ualberta.ca.

Copyright (C) 2002 Society for Neuroscience $0270-6474 / 02 / 228277-10 \$ 15.00 / 0$
}

1) (Wahlsten, 1989). This developmental variability within a genetically homogeneous strain provides a well controlled experiment of nature to assess the behavioral effects of an absent CC. Surprisingly, hereditary absence of the CC has little or no impact on a wide range of mouse behaviors (Schmidt et al., 1991; Bulman-Fleming et al., 1992; Wahlsten et al., 2001).

By creating recombinant inbred lines from a cross of BALB/c and 129 mice, a new inbred strain (9XCA/Wah) has been generated that displays a more severe forebrain commissural defect than either progenitor strain: total $\mathrm{CC}$ deletion and a severely reduced $\mathrm{HC}$ are evident in every animal of this strain (Wahlsten and Sparks, 1995) (D. Wahlsten and K. M. Bishop, unpublished observations). In a large sample of 162 mice, the BALB/cWah1 strain showed partial or total absence of the CC in $44 \%$ of mice and reduction of the $\mathrm{HC}$ in only $4 \%$. The $\mathrm{HC}$ was reduced only when the $\mathrm{CC}$ was totally absent. Thus, the principal difference between the BALB/cWah1 and 9XCA/Wah strains is the size of the $\mathrm{HC}$, which is almost always normal in BALB/cWah1 but is always severely reduced in 9XCA/Wah. 9XCA/Wah is the only strain known to have a severely reduced $\mathrm{HC}$, and it presents a unique opportunity for investigating the functional consequences of gross reduction of hippocampal commissural inputs.

Hippocampal long-term potentiation (LTP) is an enhancement of synaptic transmission that may be important for regulating the expression of specific types of learning and memory (for review, see Bliss and Collingridge, 1993; Martin et al., 2000). The absence of intact interhemispheric connections, such as the HC, may impair memory function by altering the expression of hip- 


\begin{tabular}{|c|c|c|c|c|}
\hline & & BALB/cWah1 & 9XCA/Wah & $p$ \\
\hline \multirow[t]{2}{*}{ Training (day 1) } & Before CS & $3 \pm 1(n=12)$ & $5 \pm 1(n=12)$ & NS \\
\hline & After US & $19 \pm 4(n=12)$ & $30 \pm 7(n=12)$ & NS \\
\hline \multirow[t]{3}{*}{ Testing (day 2) } & Contextual & $46 \pm 6(n=12)$ & $46 \pm 6(n=12)$ & NS \\
\hline & Acclimation & $2 \pm 1(n=12)$ & $8 \pm 2(n=12)$ & $<0.01$ \\
\hline & Cued & $34 \pm 7(n=12)$ & $35 \pm 6(n=12)$ & NS \\
\hline \multirow[t]{4}{*}{ Contextual extinction } & Day 3 & $27 \pm 3(n=7)$ & $53 \pm 4(n=7)$ & $<0.001$ \\
\hline & Day 5 & $20 \pm 5(n=7)$ & $32 \pm 5(n=7)$ & $<0.05$ \\
\hline & Day 7 & $10 \pm 3(n=7)$ & $18 \pm 6(n=7)$ & NS \\
\hline & Day 9 & $6 \pm 1(n=7)$ & $16 \pm 4(n=7)$ & $<0.02$ \\
\hline \multirow[t]{7}{*}{ Cued extinction (day 2) } & Acclimation & $4 \pm 2(n=12)$ & $20 \pm 5(n=8)$ & $<0.01$ \\
\hline & Trial block 1 & $22 \pm 3(n=12)$ & $23 \pm 3(n=8)$ & NS \\
\hline & Trial block 2 & $24 \pm 3(n=12)$ & $17 \pm 3(n=8)$ & NS \\
\hline & Trial block 3 & $22 \pm 3(n=12)$ & $18 \pm 3(n=8)$ & NS \\
\hline & Trial block 4 & $18 \pm 3(n=12)$ & $16 \pm 3(n=8)$ & NS \\
\hline & Trial block 5 & $19 \pm 3(n=12)$ & $15 \pm 4(n=8)$ & NS \\
\hline & Trial block 6 & $20 \pm 4(n=12)$ & $21 \pm 5(n=8)$ & NS \\
\hline
\end{tabular}

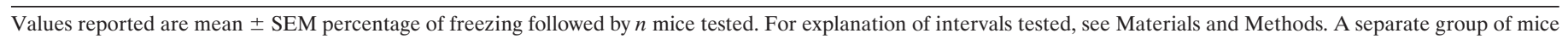
was used for cued extinction testing. $p$ values were derived from Student's $t$ test, and significance was considered $p<0.05$. NS, Not significantly different.

pocampal LTP, but, to date, this hypothesis has not been tested. We present here the first conjoint assessment of hippocampal synaptic plasticity and behavioral learning and memory in mice with substantial reduction of the HC. We addressed two questions: (1) does the absence of the $\mathrm{CC}$ and/or HC impair hippocampal synaptic plasticity? and (2) are hippocampus-dependent learning and memory altered by agenesis of the $\mathrm{CC}$ and/or HC? Our results reveal the importance of an intact $\mathrm{HC}$ in regulating both hippocampal synaptic plasticity and hippocampus-dependent memory function.

\section{MATERIALS AND METHODS}

Animals. Two closely related strains of mice (aged $>8$ weeks), from the colony of D. Wahlsten, were compared in this study. BALB/cWah1 was derived from BALB/cJ (Wahlsten, 1989), whereas 9XCA/Wah was created by inbreeding a line of mice from the $F_{2}$ hybrid cross of BALB/ cWah1 and 129P1/ReJ (Wahlsten and Sparks, 1995) (Wahlsten and Bishop, unpublished observations). The 9XCA strain has experienced $>25$ generations of full-sibling inbreeding. All mice were maintained at $\sim 22^{\circ} \mathrm{C}$ with room lights activated from 6:00 A.M. to 6:00 P.M. Mice were group housed in plastic cages $(29 \times 18 \times 13 \mathrm{~cm})$ filled with Aspen Chip bedding (Northeastern Products, Warrensburg, NY) that was changed once per week. They had access to tap water and solid food ad libitum (Laboratory Rodent Diet 5001; Purina Mills, St. Louis, MO). Care and experimental procedures followed guidelines approved by the Canadian Council on Animal Care. Behavioral fear conditioning experiments were performed first, followed by LTP experiments using hippocampal slices from the same, previously conditioned animals.

Fear conditioning. Mice were individually placed in a clear, Plexiglas conditioning chamber (Med Associates, E. Fairfield, VT) for training. A tone [conditioned stimulus (CS)] of $85 \mathrm{~dB}$ intensity and $30 \mathrm{sec}$ duration was activated after a 2 min acclimation period in the chamber. Mice received a $2 \mathrm{sec}$ foot shock [unconditioned stimulus (US)] of $0.7 \mathrm{~mA}$ intensity during the last $2 \mathrm{sec}$ of the CS. The mice remained in the chamber for $30 \mathrm{sec}$ after the foot shock. Twenty-four hours later, mice were returned to the chamber for a 5 min contextual test in the absence of the tone or foot shock. After a $1 \mathrm{hr}$ waiting period, the mice were exposed to an alternate chamber (of different shape but the same area, with a black plastic floor and wall material that were lemon scented) for a 5 min cued test interval, in which the CS tone was presented during the final $3 \mathrm{~min}$.

For a subset of the mice, contextual extinction was assessed starting the day after testing. Mice were returned to the Plexiglas conditioning chamber for a 5 min trial on days $3,5,7$, and 9 after training on day 1 . A separate group of mice was tested for cued extinction only. These animals were placed in the same Plexiglas conditioning chamber used for training and contextual testing. After a 2 min acclimation period, a $2 \mathrm{~min}$ $\mathrm{CS}(85 \mathrm{~dB}$ tone) was presented that coterminated with a $2 \mathrm{sec}$ pulse of $0.7 \mathrm{~mA}$ foot shock. The mice remained in the chamber for $30 \mathrm{sec}$ after foot shock. Twenty-four hours later, the mice were given 30 extinction trials of $2 \mathrm{~min}$ duration each ( $5 \mathrm{sec}$ intertrial interval), during which the $\mathrm{CS}$ was presented. The next day, animals were returned to the chamber for a long-term memory test consisting of 2 min acclimation, followed by a 5 min CS.

Conditioning throughout training, testing, and extinction was measured by assessing freezing behavior every $5 \mathrm{sec}$. Mice were classified as frozen whenever complete absence of motion was evident (respiration excluded). The percentage of time spent frozen was calculated for each mouse in discrete time intervals, and these results were pooled and averaged for each strain in each interval. Averaged data for fear conditioning are presented in Table 1.

Electrophysiology: extracellular field recordings. Transverse hippocampal slices (400 $\mu \mathrm{m}$ thickness) were cut and maintained in an interface chamber at $28^{\circ} \mathrm{C}$ (for more details, see Nguyen et al., 2000b). The artificial CSF (ACSF) used for dissection and superfusion contained the following (in mM): $125 \mathrm{NaCl}, 4.4 \mathrm{KCl}, 1.5 \mathrm{MgSO}_{4}, 1 \mathrm{NaH}_{2} \mathrm{PO}_{4}, 26$ $\mathrm{NaHCO}_{3}, 10$ glucose, and $2.5 \mathrm{CaCl}_{2}$. For some paired-pulse facilitation (PPF) experiments, the extracellular $\mathrm{Ca}^{2+}$ concentration was reduced to $0.5 \mathrm{~mm}$. Extracellular field EPSPs (fEPSPs) were recorded in stratum radiatum of area CA1 using glass microelectrodes (resistances, 2-4 M $\Omega$ ) filled with ACSF. The Schaeffer collateral (SC) pathway was stimulated with bipolar nickel-chromium electrodes positioned in stratum radiatum. Evoked fEPSPs were recorded, digitized, and analyzed using pClamp 7 software (Axon Instruments, Union City, CA). The mossy fiber (MF) pathway was stimulated near the granule cell bodies of the dentate gyrus, and evoked fEPSPs were recorded from the proximal apical dendrites of the pyramidal cell bodies in stratum radiatum of area CA3. Confirmation that fEPSP responses were elicited from the MF pathway was done by addition of an agonist of group II metabotropic glutamate receptors [20 $\mu \mathrm{M}$ L-CCG-1 (2S,1'S,2'S)-2-(carboxycyclopropyl)glycine); Research Biochemicals, Natick, MA] that selectively reduces synaptic responses in the MF pathway (Tzounopoulos et al., 1998). Baseline fEPSPs were elicited once per minute at a stimulus intensity $(0.08 \mathrm{msec}$ pulse width $)$ that evoked fEPSP amplitudes that were $40 \%$ of maximal sizes. Various stimulation protocols were used to induce LTP; these are described at appropriate parts of Results. D(-)-2-amino-5-phosphonopentanoic acid (AP-5), an NMDA receptor (NMDAR) antagonist (Research Biochemicals), was prepared as a $50 \mathrm{~mm}$ stock solution in $\mathrm{dH}_{2} 0$, and it was diluted to $50 \mu \mathrm{M}$ in ACSF before bath application.

Data analysis. We assessed LTP, the relationship between presynapticfiber volley amplitude and fEPSP slope, and PPF in hippocampal slices from the two strains. The average fEPSP slope during stable recordings 


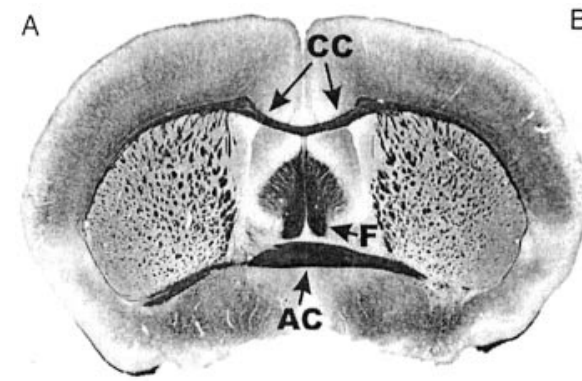

C

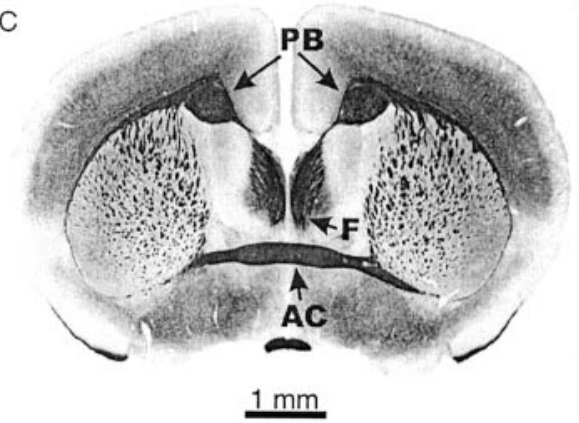

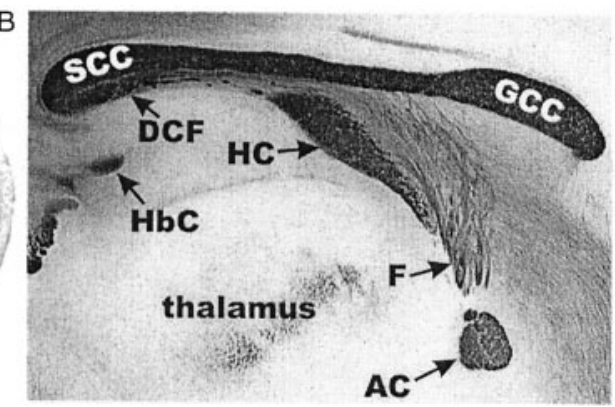

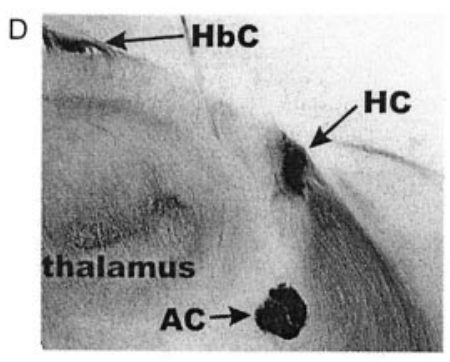

$1 \mathrm{~mm}$
Figure 1. Brain morphology of normal and acallosal mice. $A$, Coronal section, normal brain: the corpus callosum spans the cerebral hemispheres. $B$, Sagittal section, normal brain: the corpus callosum extends rostrocaudally along the midline of the brain. $C$, Coronal section, acallosal brain: there is no corpus callosum, and fibers have turned to form the Probst bundle. D, Sagittal section, acallosal brain: there is no corpus callosum, and the hippocampal commissure is reduced in size. $A C$, Anterior commissure; $D C F$, dorsal commissure of the fornix; $F$, columns of the fornix; $G C C$, genu of the $\mathrm{CC} ; \mathrm{HbC}$, habenular commissure; $P B$, Probst bundle; $S C C$, splenium of the CC. before LTP induction was calculated for each experiment, and, unless otherwise stated, fEPSP slopes were measured at $45 \mathrm{~min}$ [for early-LTP (E-LTP) and MF experiments] or at $120 \mathrm{~min}$ [for late-LTP (L-LTP) experiments] after high-frequency stimulation (HFS). fEPSP slopes recorded after HFS were normalized in relation to pretetanization "baseline" averages. fEPSPs were averaged within each strain, and the resulting means were compared across strains (Nguyen et al., 2000b). Student's $t$ test was used to determine whether there was a significant difference $(p<0.05)$ between the two strains. Presynaptic fiber volley amplitudes and fEPSP slopes, measured by varying the stimulus intensity, were plotted, and a linear regression was done for each strain. Student's $t$ test was used to assess statistical significance between linear regression slopes. For PPF, data were analyzed as described by Nguyen et al. (2000a). One-way ANOVA and Tukey-Kramer post hoc tests were done for each interpulse interval to determine which groups were significantly different.

Anatomy. The myelin-stained brain sections shown in Figure 1 were prepared from mice killed by intraperitoneal injection of $120 \mathrm{mg} / \mathrm{kg}$ pentobarbital sodium. After being killed, animals were perfused with 10 $\mathrm{ml}$ of $4 \%$ paraformaldehyde, followed by $20 \mathrm{ml}$ of physiological saline. For coronal images, frozen sections were cut at a thickness of $25 \mu \mathrm{m}$ and mounted on glass slides. Sections containing the center of the anterior commissure were selected for staining, and these were stained for myelin by using the gold chloride method (Schmued, 1990). For sagittal images, brains were removed from animals after they were killed and immersed in $10 \%$ formalin or $4 \%$ paraformaldehyde for fixation. Whole brains were bisected along the midsagittal plane, and one-half was stained en bloc using Schmued's gold chloride method. Half-brains from some animals that received cued fear extinction were stained and analyzed for $\mathrm{CC}$ and $\mathrm{HC}$ integrity. No significant differences were found in cued fear extinction performance within strains, despite varying levels of CC integrity in BALB/cWah1 (data not shown), thereby allowing data to be combined within strains.

\section{RESULTS}

\section{Commissural anatomy}

Although the procedure used to prepare the hippocampal slices often damaged the forebrain commissures, satisfactory anatomical descriptions of most animals used in this study were obtained. Figure 2 compares the commissures of $13 \mathrm{BALB} / \mathrm{cWah} 1$ and eight 9XCA/Wah mice. Only one BALB/cWah1 mouse showed an abnormally small $\mathrm{HC}$, whereas the $\mathrm{HC}$ was severely deficient in every 9XCA/Wah animal, including two in which there were almost no $\mathrm{HC}$ axons crossing the midline. There was a wide range of size of the $\mathrm{CC}$ in $\mathrm{BALB} / \mathrm{cWah} 1$ mice, but this extreme size variation within $\mathrm{BALB} / \mathrm{cWah} 1$ was not significantly related to fear conditioning (data not shown), which is consistent with the literature on behavioral sparing in CC agenesis (Schmidt et al., 1991; Bulman-Fleming et al., 1992; Wahlsten et al., 2001). As such, the focus of our analysis was on the difference between strains that arose from grossly different sizes of the HC.

\section{Fear conditioning is comparable in strains BALB/cWah1 and 9XCA/Wah}

Does loss of commissural input to the hippocampus alter memory function? Lesion studies have shown contextual fear conditioning to be dependent on the hippocampus (Kim and Fanselow, 1992; Chen et al., 1996) and on the amygdala (Phillips and LeDoux, 1992; Kim et al., 1993). In contrast, cued (tone) fear conditioning relies primarily on the amygdala (Fanselow and Kim, 1994). Both contextual and cued fear conditioning are dependent on NMDA receptor activation (Fanselow and Kim, 1994; Fanselow et al., 1994; Walker and Davis, 2002). Contextual fear conditioning was tested to determine whether a hippocampus-dependent deficit in fear memory was present in mice that display a reduced $\mathrm{HC}$, and cued fear conditioning was tested to determine whether there was an amygdala-dependent deficit in fear memory in these mice.

As shown in Figure $3 A$ and Table 1, the two strains exhibited comparable levels of freezing during the training session. Performance was not significantly different on the $24 \mathrm{hr}$ contextual fear memory test (BALB/cWah1, $46 \pm 6 \%, n=12 ; 9 X C A / W a h, 46 \pm$ $6 \%, n=12 ; p>0.05)$. However, 9XCA/Wah exhibited greater freezing during acclimation (no CS) before the cued fear memory test (BALB/cWah1, $2 \pm 1 \%, n=12$; 9XCA/Wah, $8 \pm 2 \%, n=$ $12 ; p<0.01)$. Therefore, freezing levels during acclimation were subtracted from freezing levels during cued testing for each animal in both strains. There was no significant difference between strains on the cued fear memory test (BALB/cWah1, $34 \pm$ $7 \%, n=12 ; 9 X \mathrm{XCA} / \mathrm{Wah}, 35 \pm 6 \%, n=12 ; p>0.05)$. 
Figure 2. Diagrams of the $\mathrm{CC}, \mathrm{HC}$, and dorsal commissure of the fornix $(D C F)$ in BALB/cWah1 and 9XCA/Wah mice. The vertical axis in each case was established by a line drawn through the centers of the $\mathrm{HC}$ and the anterior commissure $(A C)$, whereas the vertical level was established by the dashed line perpendicular to the vertical axis and $1.5 \mathrm{~mm}$ above the center of the AC, which is not shown in these diagrams. In the 9XCA/Wah strain, every animal showed total absence of the $\mathrm{CC}$ and dorsal commissure of the fornix, as well as severe reduction of the HC. In BALB/cWah1, several patterns were seen, and the frequency of mice with each type is indicated by $X_{-}$. For example, $X 4$ means that four mice had a normal $\mathrm{HC}$ but no dorsal commissure of the fornix. Only one BALB/cWah1 mouse had an $\mathrm{HC}$ as small as the largest $\mathrm{HC}$ among 9XCA/Wah mice.

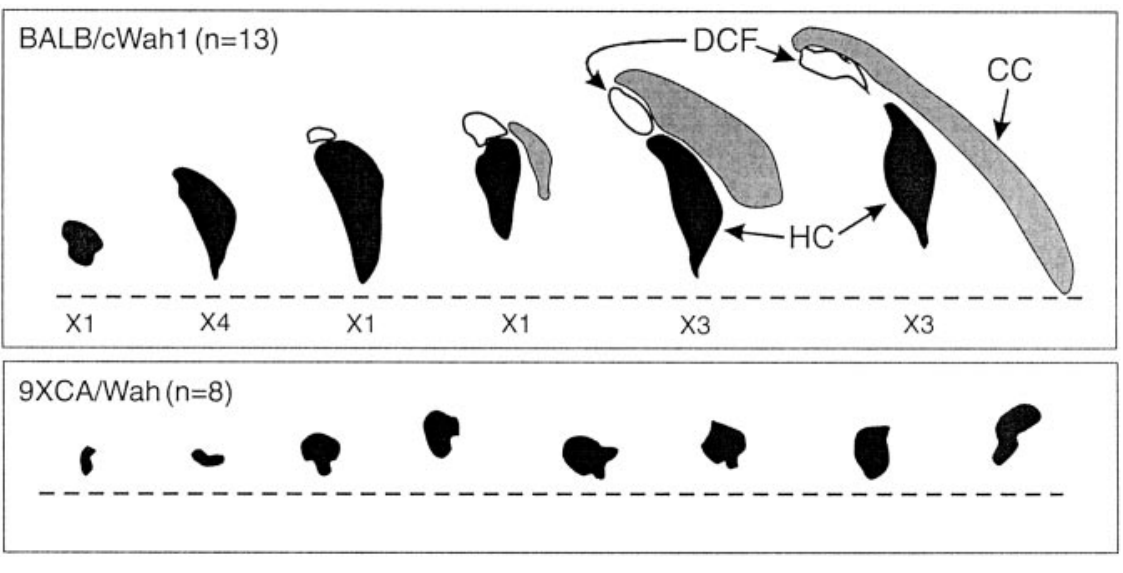

\section{Mice with a reduced $\mathrm{HC}$ exhibit deficits in contextual extinction that are likely hippocampus dependent}

Extinction of fear entails repeated exposure of animals to a CS that they were previously trained to fear, until the fear response to the CS is reduced. Pavlov (1927) proposed that extinction involved the learning of new information and not the erasure of old memories. Both strains were tested for contextual and cued fear extinction as described in Materials and Methods. Mice exhibiting reduction of the $\mathrm{HC}$ (strain 9XCA/Wah) were deficient in contextual fear extinction (Fig. $3 B$ ). These mice showed significantly higher levels of freezing than BALB/cWah1 (for data, see Table 1), such that they exhibited an increased latency to learn to dissociate the CS (context) from the US (foot shock) and showed higher freezing levels at the end of testing trials (BALB/ cWah1, $6 \pm 1 \%, n=7$; 9XCA/Wah, $16 \pm 4 \%, n=7 ; p<0.05)$.

A separate group of mice was tested for cued extinction (Fig. $3 C$ ). Before the cued extinction trials, mice were given a $2 \mathrm{~min}$ acclimation period without CS. As in the cued fear conditioning test, 9XCA/Wah showed a significantly higher level of freezing during acclimation than BALB/cWah1 (BALB/cWah1, $4 \pm 2 \%$, $n=12 ; 9 X C A / W a h, 20 \pm 5 \%, n=8 ; p<0.01)$. Thus, individual acclimation scores were subtracted for each animal (in both strains). No significant difference was found between strains for any of the six cued extinction trial blocks (for data, see Table 1). Because contextual, but not cued, extinction was impaired in 9XCA/Wah, these results suggest a hippocampal deficit in learning to dissociate the CS from the US in mice that have a reduced HC.

\section{Paired-pulse facilitation is deficient in mice with a reduced $\mathrm{HC}$}

Does absence of an intact HC compromise short-term synaptic plasticity? One type of short-term plasticity that is prominent at hippocampal synapses is PPF. PPF is an enhancement of synaptic transmission during the second of two closely spaced stimuli (Katz and Miledi, 1968). PPF occurs because the calcium entering the presynaptic terminal after the first stimulus pulse is not completely cleared before a closely spaced, subsequent stimulus pulse. The residual calcium left over after the first pulse sums with the presynaptic calcium influx of the second pulse to elicit enhanced transmitter release during the second stimulus pulse (Katz and Miledi, 1968).

PPF was examined in the SC pathway at interpulse intervals of 50, 75, and $100 \mathrm{msec}$ in both strains. In addition, PPF was examined in slices from both strains during perfusion with ACSF containing reduced levels of $\mathrm{Ca}^{2+}$ (see Materials and Methods).
As shown in Figure 4, PPF in standard ACSF was significantly reduced in strain $9 \mathrm{XCA} / \mathrm{Wah}$ compared with $\mathrm{BALB} / \mathrm{cW}$ ah1 at 75 $\operatorname{msec}(\mathrm{BALB} / \mathrm{cWah} 1,58 \pm 3 \%, n=27 ; 9 \mathrm{XCA} / \mathrm{Wah}, 42 \pm 2 \%$, $n=51 ; p<0.05)$ and $100 \mathrm{msec}$ interpulse intervals (BALB/ cWah1, $47 \pm 2 \%, n=49 ; 9 X C A / W a h, 35 \pm 2 \%, n=68 ; p<$ $0.01)$. However, reduced extracellular $\mathrm{Ca}^{2+}$ rescued PPF in strain 9XCA/Wah, such that PPF was now not significantly different from BALB/cWah1 PPF measured in standard ACSF at interpulse intervals of $50 \mathrm{msec}(\mathrm{BALB} / \mathrm{cWah} 1,60 \pm 3 \%, n=49$; 9XCA/Wah $\left.\downarrow\left[\mathrm{Ca}^{2+}\right], 70 \pm 7 \%, n=20 ; p>0.05\right), 75 \mathrm{msec}$ $\left(\mathrm{BALB} / \mathrm{cWah} 1,58 \pm 3 \%, n=27 ; 9 \mathrm{XCA} / \mathrm{Wah} \downarrow\left[\mathrm{Ca}^{2+}\right], 57 \pm\right.$ $7 \%, n=20 ; p>0.05)$, and $100 \mathrm{msec}(\mathrm{BALB} / \mathrm{cWah} 1,47 \pm 2 \%$, $\left.n=49 ; 9 \mathrm{XCA} / \mathrm{Wah} \downarrow\left[\mathrm{Ca}^{2+}\right], 48 \pm 6 \%, n=20 ; p>0.05\right)$. Decreasing the probability of transmitter release by reducing extracellular $\left[\mathrm{Ca}^{2+}\right]$ leaves more transmitter available to be released in response to the second pulse. Thus, in standard ACSF, 9XCA/Wah CA3 pyramidal neurons may possess altered intracellular calcium dynamics and/or higher basal transmitter release compared with BALB/cWah1. Consistent with these hypotheses, we found that, in BALB/cWah1 neurons, reduced extracellular $\left[\mathrm{Ca}^{2+}\right]$ increased PPF substantially at all three interpulse intervals tested ( $p<0.001$ compared with normal ACSF) (Fig. 4). Thus, reduction of the HC impaired hippocampal PPF in area CA1, and this deficit in short-term synaptic plasticity was rescued by reducing the extracellular calcium concentration.

\section{LTP in two pathways does not require fully intact interhemispheric connections}

Hippocampal LTP is an activity-dependent strengthening of synaptic transmission believed to be important for regulating information storage in the mammalian brain (Bliss and Lömo, 1973; Moser et al., 1998; Martin et al., 2000; Brun et al., 2001). Area CA1 of the hippocampus is particularly important for learning and memory in humans and in rodents (Zola-Morgan et al., 1986; Tsien et al., 1996), and, thus, synaptic modifications in this subregion of the hippocampus may contribute to the modification of hippocampus-dependent aspects of memory function, such as contextual fear extinction. Does the absence of an intact $\mathrm{HC}$ alter LTP in area CA1?

LTP was examined in the SC pathway in hippocampal slices from strains BALB/cWah1 and 9XCA/Wah. The early and late temporal phases of LTP (E-LTP and L-LTP) in the SC pathway differ in their optimal induction requirements (for review, see Huang et al., 1996). Two patterns of stimulation were used to induce E-LTP: twin bursts of $100 \mathrm{~Hz}$ (1 sec duration) delivered at a $20 \mathrm{sec}$ interburst interval and theta-burst stimulation (TBS). 
A

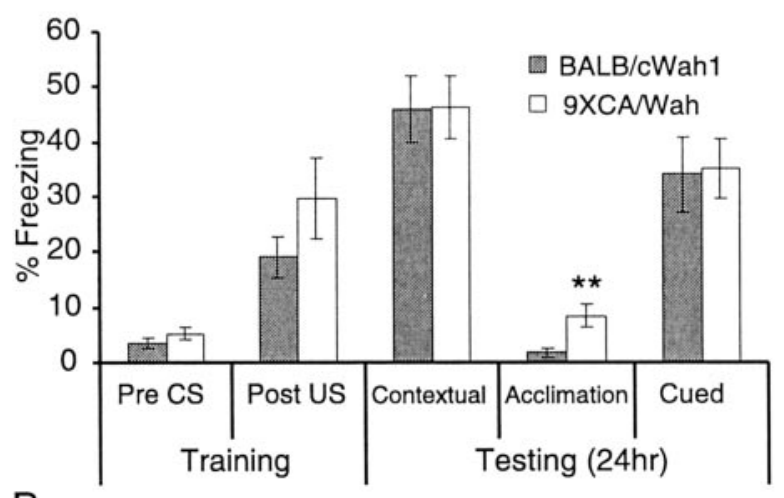

B

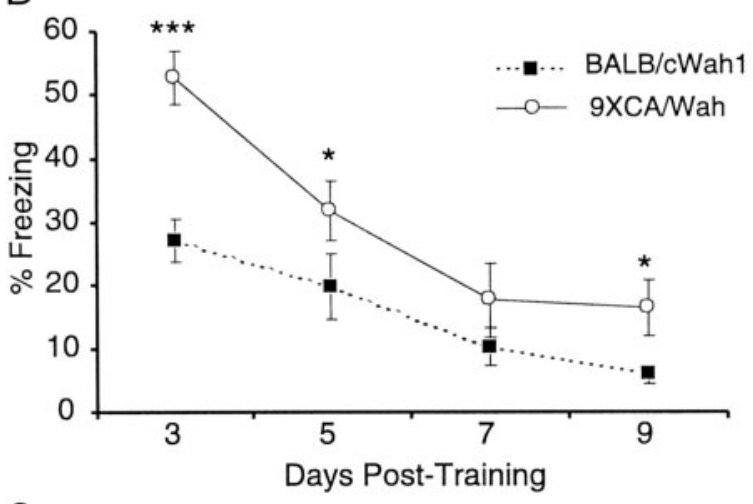

C

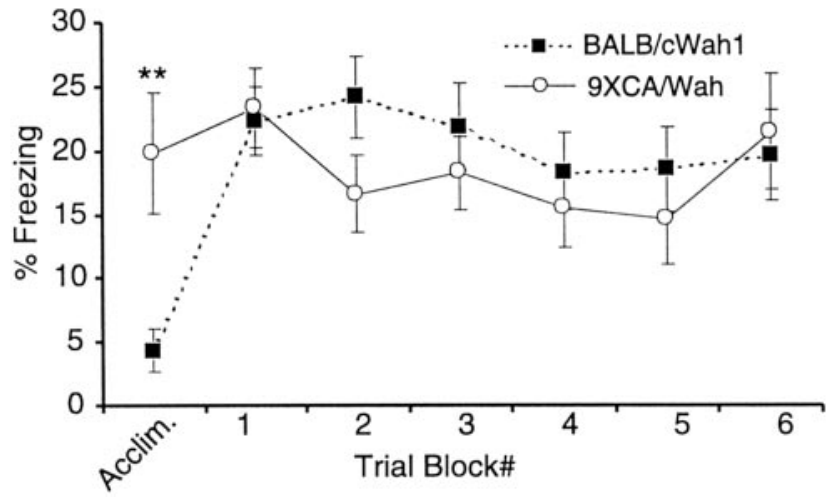

Figure 3. A reduced HC impairs contextual fear extinction but does not affect cued and contextual fear conditioning. $A, \mathrm{BALB} / \mathrm{cWah} 1(n=12)$ and 9XCA/Wah $(n=12)$ performed normally on tests of $24 \mathrm{hr}$ contextual and cued memory. Both strains displayed significantly different levels of freezing for "acclimation" during a 2 min test interval in a novel context, before presentation of the CS for the cued memory test. Thus, acclimation freezing values were subtracted for each mouse (both strains) to calculate percentage of freezing for the cued memory test. Cued memory was not significantly different between strains. $B$, Both strains received 5 min contextual extinction trials $3,5,7$, and $9 \mathrm{~d}$ after training. 9XCA $(n=$ 7) exhibited delayed contextual extinction compared with BALB/cWah1 $(n=7)$, and they still showed less extinction during the final trial on day 9. $C$, Separate groups of mice from both strains received a 2 min acclimation interval, followed by 302 min cued extinction trials $(5 \mathrm{sec}$ intertrial interval) the day after training. Cued extinction trials were grouped into six blocks of five trials each. 9XCA/Wah again showed significantly greater freezing during acclimation, so acclimation values for each mouse (both strains) were subtracted for all subsequent cued extinction trials. There was no significant difference between BALB/cWah1 $(n=12)$ and 9XCA/Wah $(n=8)$ for any trial block during cued extinction. Asterisks indicate significance values derived from Student's $t$ test $\left({ }^{*} p<0.05 ;{ }^{* *} p<\right.$ $0.01 ; * * p<0.0001)$. CS, Tone; US, foot shock.

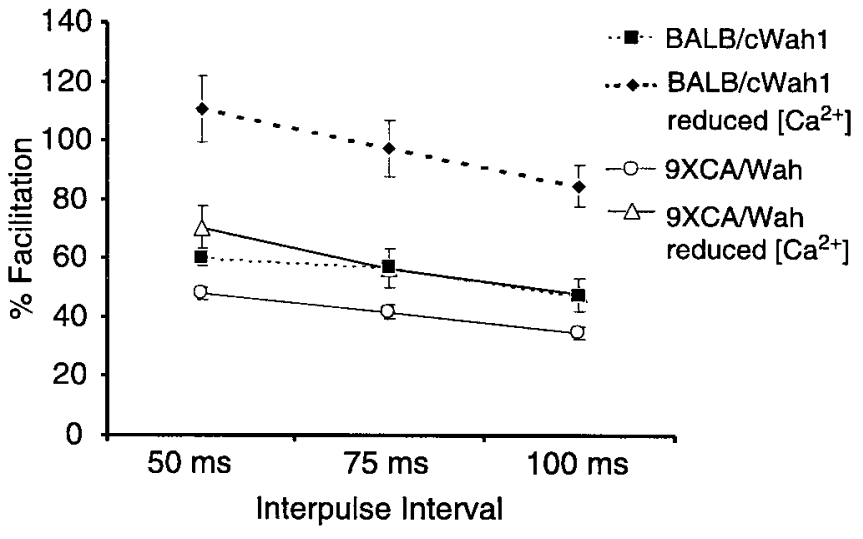

Figure 4. Paired-pulse facilitation is decreased in mice with a reduced $\mathrm{HC}$ and is rescued by reduced extracellular $\left[\mathrm{Ca}^{2+}\right]$. Plot of percentage of facilitation [ratio of fEPSP slopes: ((pulse 2/pulse 1) - 1) $\times 100$ ] versus interpulse interval for strains BALB/cWah1 and 9XCA/Wah. In standard ACSF, 9XCA/Wah exhibited significantly less facilitation than BALB/ cWah1. When measured under conditions of reduced extracellular $\left[\mathrm{Ca}^{2+}\right]$, facilitation in 9XCA/Wah was not significantly different from that seen in BALB/cWah1 slices in standard ACSF. Reduced extracellular $\left[\mathrm{Ca}^{2+}\right]$ also significantly increased facilitation in BALB/cWah1.

TBS consisted of 15 bursts of four pulses at $100 \mathrm{~Hz}$, delivered at an interburst interval of 200 msec. Twin-burst HFS resulted in a mean fEPSP slope value of $156 \pm 16 \%(n=10)$ at $45 \mathrm{~min}$ after HFS in BALB/cWah1 slices and a corresponding mean fEPSP slope value of $159 \pm 13 \%(n=9)$ in $9 \mathrm{XCA} /$ Wah slices $(p>0.5$ for interstrain comparison) (Fig. $5 A$ ). There was also no significant difference between strains for TBS-LTP at 45 min after HFS $(\mathrm{BALB} / \mathrm{cWah} 1,151 \pm 14 \%, n=8 ;$ 9XCA/Wah, $141 \pm 10 \%, n=$ $10 ; p>0.5)$ (Fig. 5B). However, both strains exhibited slightly lower potentiation than that observed in $\mathrm{C} 57 \mathrm{BL} / 6$ mice in previous studies that used identical methods (Nguyen et al., 2000a).

Is L-LTP affected by the absence of an intact HC? Multiple bursts of HFS induce L-LTP in mouse hippocampal slices (Nguyen et al., 2000a,b; Woo et al., 2000). A tetra-burst pattern was used in our experiments: four trains of $100 \mathrm{~Hz}(1 \mathrm{sec}$ duration), with an interburst interval of $20 \mathrm{sec}$ (Woo et al., 2000). The mean fEPSP slope in BALB/cWah1 slices measured $120 \mathrm{~min}$ after tetra-burst HFS was $157 \pm 19 \%(n=5)$, and this was not significantly different from the corresponding mean fEPSP slope measured in 9XCA/Wah slices $(147 \pm 8 \% ; n=11 ; p>0.5)$ (Fig. $5 C$ ). However, these values were smaller than those reported previously for C57BL/6 mice (Nguyen et al., 2000b). The mean fEPSP slopes resulting from more temporally spaced tetra-burst HFS (5 min interburst interval) also were not significantly different between strains (BALB/cWah1, $179 \pm 19 \%, n=4$; 9XCA/ Wah, $217 \pm 27 \%, n=9 ; p>0.1$ ) (Fig. $5 D$ ), and they were similar to those reported previously for C57BL/6 mice (Nguyen et al., 2000a). Thus, reduction of the HC produced no significant impairments in either E-LTP or L-LTP in area CA1.

Pyramidal cells in hippocampal area CA3 receive two excitatory synaptic inputs from the MF and the associational-commissural (assoc-com) pathways (Andersen et al., 1966). It is possible that, in strain 9XCA/Wah, which exhibits agenesis of the hippocampal commissure, MF LTP is altered as a result of the absence of the assoc-com input. Thus, we examined MF LTP in slices from both inbred strains, BALB/cWah1 and 9XCA/Wah.

MF LTP is NMDA receptor independent (Harris and Cotman, 1986), but it is dependent on presynaptic $\mathrm{Ca}^{2+}$ influx 
A

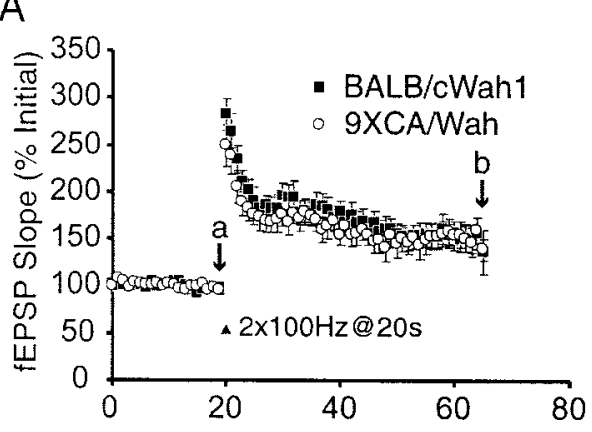

$\mathrm{C}$
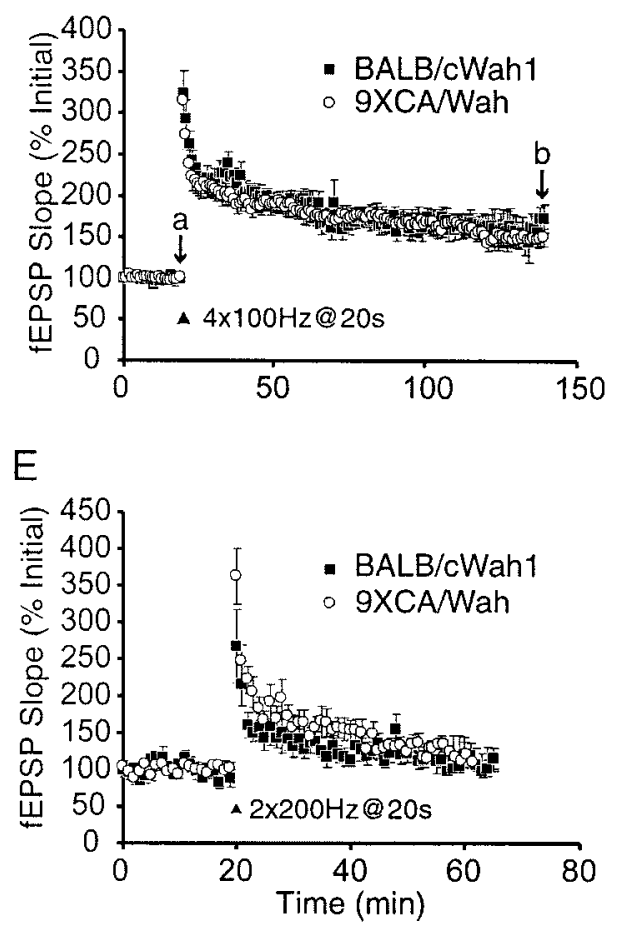

B
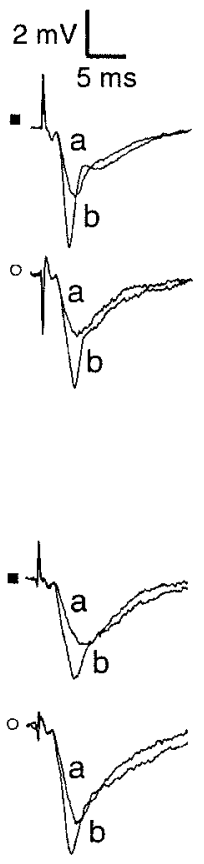

$F$

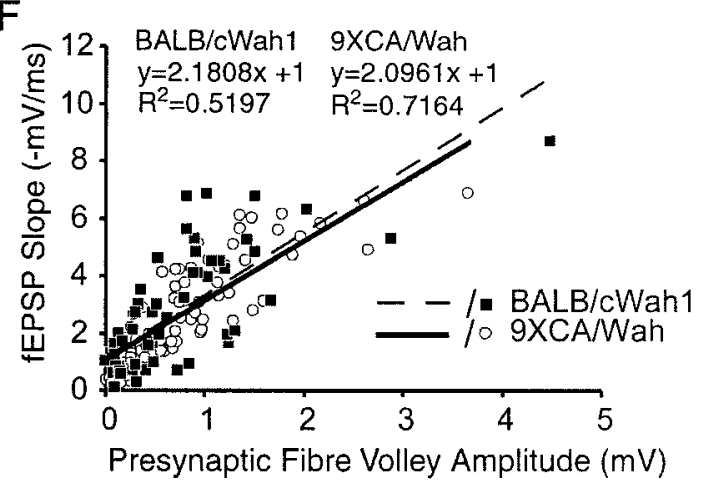

Figure 5. Hippocampal LTP in two pathways is normal in mice with a reduced HC. $A, B$, E-LTP in the Schaffer collateral pathway is not significantly different between strains. $A$, Plot of fEPSP slope versus time, comparing averaged responses from BALB/cWah1 $(n=10$ slices) and 9XCA/Wah $(n=$ 9 slices $)$. LTP was elicited by twin bursts of $100 \mathrm{~Hz}(2 \times 100 \mathrm{~Hz} @ 20 \mathrm{sec}) . \mathrm{B}$, Average responses from BALB/cWah1 $(n=8)$ and $9 \mathrm{XCA} / \mathrm{Wah}(n=10)$ for TBS. $C, D$, L-LTP in the Schaffer collateral pathway is not significantly different between strains. $C$, LTP was elicited by four bursts of $100 \mathrm{~Hz}$ $(4 \times 100 \mathrm{~Hz} @ 20 \mathrm{sec})$ in BALB/cWah1 ( $n=5$ slices) and 9XCA/Wah $(n=11$ slices). $D$, LTP was elicited by four spaced bursts of $100 \mathrm{~Hz}$, interburst interval of $5 \mathrm{~min}(4 \times 100 \mathrm{~Hz} @ 5 \mathrm{~min})$ in BALB/cWah1 $(n=4$ slices $)$ and 9XCA/Wah $(n=9$ slices $) . E$, E-LTP in the mossy fiber pathway, elicited by twin bursts of $200 \mathrm{~Hz}(2 \times 200 \mathrm{~Hz} @ 20 \mathrm{sec})$ in BALB/cWah1 $(n=9$ slices $)$ and 9XCA/Wah $(n=17$ slices $)$, was not significantly different between strains. $F$, Input-output curve slopes (fEPSP slope vs presynaptic fiber volley amplitude) are not significantly different between BALB/cWah1 $(n=11$ slices, 5 data points per slice) and 9XCA/Wah $(n=17$ slices, 5 data points per slice). Data are shown as mean \pm SEM. Sample fEPSP traces were recorded at times $a$ and $b$ indicated on the graphs.

(Zalutsky and Nicoll, 1990) (for review, see Nicoll and Malenka, 1995). To ensure that MF, and not assoc-com, LTP was measured in CA3, we bath applied $50 \mu \mathrm{M}$ AP-5 starting at $10 \mathrm{~min}$ before tetanization and ending at $10 \mathrm{~min}$ after HFS. MF LTP was induced using two trains of $200 \mathrm{~Hz}$ (1 sec duration each), delivered at a $20 \mathrm{sec}$ intertrain interval. The mean fEPSP slope at 45 min after HFS was $114 \pm 14 \%(n=9)$ in BALB/cWah1 and $111 \pm 13 \%(n=17 ; p>0.5)$ in $9 X C A / W a h$ (Fig. $5 E)$. Thus, MF LTP was not significantly altered by the absence of an intact $\mathrm{HC}$.

Does reduction of the $\mathrm{HC}$ change basal synaptic input-output relationships? The presynaptic fiber volley amplitude and initial fEPSP slope were measured from single fEPSP sweeps elicited in the SC pathway of area CA1 of several hippocampal slices, using a range of stimulus intensities. The fiber volley size is proportional to the number of presynaptic axons recruited by stimulation, and the initial fEPSP slope is a measure of synaptic strength (Johnston and $\mathrm{Wu}, 1995)$. A trendline fit to plotted data points was generated using linear regression analysis (Fig. $5 F$ ). These positive trendline slopes indicate that postsynaptic responses increased as the magnitude of presynaptic stimulation increased. Both strains showed fEPSP slopes that were not significantly different from one another over a range of stimulation intensities and presynaptic volley sizes (BALB/cWah1, $y=2.1808 x+1$, $\left.R^{2}=0.5197 ; 9 X C A / W a h, y=2.0961 x+1, R^{2}=0.7164 ; p>0.5\right)$ (Fig. $5 F$ ). Thus, basal hippocampal synaptic transmission and presynaptic fiber recruitment in the SC pathway were unaffected by the absence of an intact HC. 
A
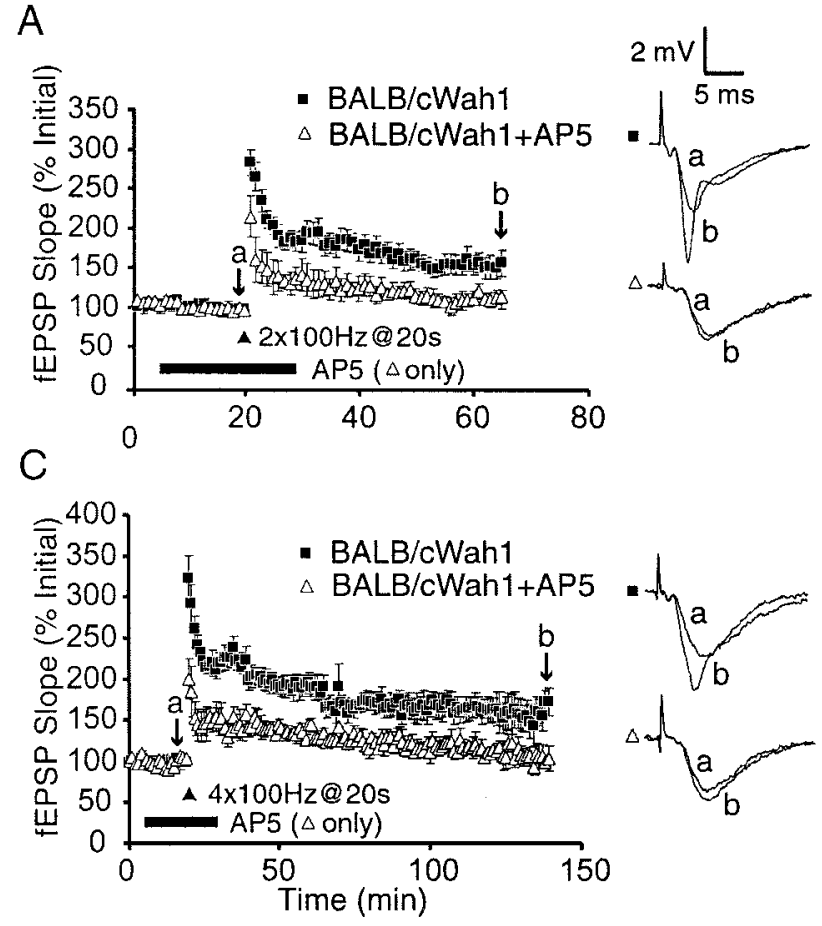

B
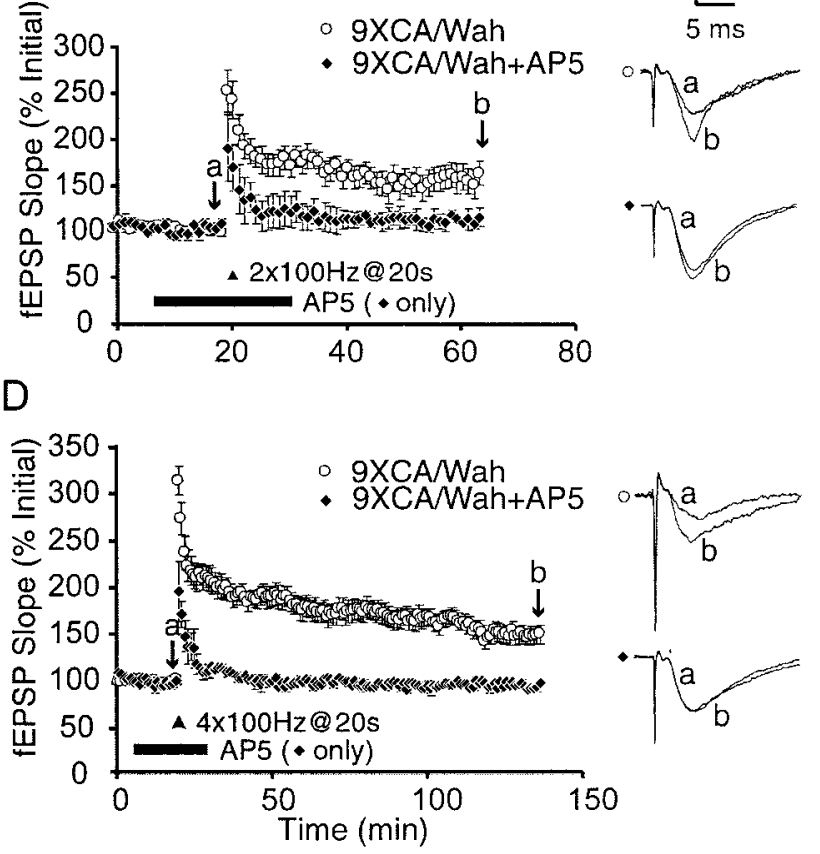

Figure 6. Early- and late-LTP in the Schaffer collateral pathway are NMDA receptor dependent in both strains. $A, B$, E-LTP elicited by twin bursts of $100 \mathrm{~Hz}(2 \times 100 \mathrm{~Hz} @ 20 \mathrm{sec})$ is significantly reduced by application of $50 \mu \mathrm{M} \mathrm{AP}-5$ in BALB/cWah1 (control, $n=10 ; \mathrm{AP}-5, n=5)$ and 9XCA/Wah (control, $n=11$; AP-5, $n=4)$. $C, D$, L-LTP elicited by four bursts of $100 \mathrm{~Hz}(4 \times 100 \mathrm{~Hz} 20 \mathrm{sec})$ is significantly reduced by AP-5 in BALB/cWah1 (control, $n=5$; AP-5, $n=4$ ) and 9XCA/Wah (control, $n=11$; AP-5, $n=4$ ). Sample fEPSP traces were recorded at times $a$ and $b$ indicated on the graphs.

\section{E-LTP and L-LTP are NMDA receptor dependent in slices from mice with a reduced HC}

Is the NMDA receptor dependence of LTP in the SC pathway reduced by the absence of an intact HC? The NMDAR antagonist AP-5 $(50 \mu \mathrm{M})$ was bath applied for $15 \mathrm{~min}$ before and $10 \mathrm{~min}$ after HFS. At 40 min after HFS, twin-burst LTP in AP-5-treated slices was significantly reduced compared with control slices in both BALB/cWah1 (control, $154 \pm 13 \%, n=10$; AP-5, $111 \pm$ $8 \%, n=5 ; p<0.05)$ and 9XCA/Wah (control, $154 \pm 11 \%, n=$ 11; AP-5, $105 \pm 9 \%, n=4 ; p<0.05$ ) (Fig. $6 A, B$ ). At $120 \mathrm{~min}$ after HFS, tetra-burst L-LTP in AP-5-treated slices was also significantly reduced compared with control experiments in both BALB/cWah1 (control, $173 \pm 17 \%, n=5$; AP-5, $104 \pm 15 \%, n=$ $4 ; p<0.01)$ and 9XCA/Wah (control, $150 \pm 10 \%, n=11$; AP-5, $98 \pm 2 \%, n=4 ; p<0.05$ ) (Fig. 6C,D). Thus, reduction of the HC does not compromise the NMDA receptor dependence of earlyand late-LTP in the SC pathway.

\section{DISCUSSION}

Our study aimed to determine whether agenesis of the CC and/or $\mathrm{HC}$ results in memory impairments that are correlated with altered hippocampal synaptic plasticity. Contextual fear extinction was impaired in mice with a reduced HC (strain 9XCA/ Wah). Like fear conditioning, extinction has been proposed to be a form of new learning rather than an erasure of existing memories (for review, see Bouton, 1993), and it is dependent on hippocampal function (Wilson et al., 1995; Frohardt et al., 2000) (see also Fox and Holland, 1998). In addition, extinction is NMDA receptor dependent (Lee and Kim, 1998; Santini et al., 2001) (but see Berman and Dudai, 2001) and requires protein synthesis (Flood et al., 1977; Berman and Dudai, 2001; Vianna et al., 2001), similar to fear conditioning. Furthermore, Berman and Dudai (2001) suggest that both fear conditioning and extinction rely on the same brain structures. Also, the prefrontal cortex (Quirk et al., 2000; Herry and Garcia, 2002) has been shown to play a role in the maintenance of cued fear extinction, indicating that extinction may be dependent on the interaction of the hippocampus with other brain regions. Thus, our observations need to be considered from a broader, more complex mechanistic perspective, one that likely involves brain regions outside of the hippocampus.

It is unclear which synaptic pathways within the hippocampus are critical for contextual extinction. However, the impaired contextual extinction in strain 9XCA/Wah was correlated with a deficit in PPF in the SC pathway. Experiments using reduced extracellular $\left[\mathrm{Ca}^{2+}\right]$ indicated that this deficient PPF may result from elevated basal transmitter release and/or altered calcium handling efficacy in neurons of the 9XCA/Wah strain. The lack of a significant difference in basal synaptic input-output relationships between these two strains suggests that altered presynaptic calcium dynamics may contribute to the impaired PPF seen in 9XCA/Wah. Thus, contextual extinction in these strains is correlated with PPF in the SC pathway, and the HC may have an important role in the acquisition of contextual extinction. Hippocampal LTP has not been definitively correlated with contextual fear extinction. Our results suggest that contextual fear extinction is poorly correlated with certain types of hippocampal LTP.

Cued and contextual fear conditioning were unaltered in mice with a reduced HC, and LTP in the SC and MF pathways of the hippocampus remained intact. Hippocampal and amygdalal LTP 
may contribute (in ways still unclear) to consolidation of memory for fear conditioning (Clugnet and LeDoux, 1990; Rogan and LeDoux, 1995; McKernan and Shinnick-Gallagher, 1997; Rogan et al., 1997; Blair et al., 2001; Schafe et al., 2001). Several types of hippocampal LTP were intact in slices from 9XCA/Wah mice, and it is interesting that contextual fear conditioning, which is hippocampus dependent, was also preserved in these mice. In contrast, gross reduction of commissural input to the hippocampus altered short-term synaptic plasticity (PPF) and selectively impaired one particular aspect of memory function, contextual memory extinction. It is noteworthy that cats with an HC transection show no transfer of conditioned learning to the opposite hemisphere when only one brain hemisphere was trained (Majkowski, 1967). Thus, one cerebral hemisphere, containing one hippocampus, can learn a CS-US association.

Interestingly, we found that the fear responses of 9XCA/ Wah mice during acclimation or during exposure to a novel environment (measured after training but before cued testing) were significantly enhanced compared with BALB/cWah1 mice. This enhanced response to a novel environment was a possible contaminant in testing for cued memory and extinction; hence, freezing levels during acclimation were subtracted from cued memory and extinction data for each animal. Exposure to novel environments has been correlated with expression of long-term depression (LTD) in the hippocampus of specific strains of rats. Manahan-Vaughan and Braunewell (1999) showed that hippocampal low-frequency stimulation in vivo during exploration of a novel environment induced LTD in the SC pathway of the hippocampus and that such stimulation increased exploratory behavior. Altered LTD may be a cellular correlate for the increased fear in a novel environment that was seen in strain 9XCA/Wah, but LTD was not examined in the present study.

The altered contextual fear extinction found in 9XCA/Wah may be caused by 129P1/ReJ alleles at loci unrelated to defects of the HC. However, Cook et al. (2002) found that contextual and cued fear conditioning were normal in 129P1/ReJ mice compared with $\mathrm{C} 57 \mathrm{BL} / 6 \mathrm{~J}$ mice. Thus, it is unlikely that the genetic contribution of 129P1/ReJ to the 9XCA/Wah strain is the sole cause of altered hippocampal synaptic transmission and impaired memory extinction. Because our strains may differ in more than one gene pertinent to reduced $\mathrm{HC}$, we cannot rule out the possibility that some of these genes may not be essential for LTP and contextual fear extinction. Definitive evidence will require identification of the specific genes involved in formation of the $\mathrm{HC}$ so that they can be backcrossed onto different inbred strain backgrounds. Alternatively, causality may be established when there is extreme phenotypic variation within a genetically uniform inbred strain. To date, however, all recombinants with defective HC showed $100 \%$ abnormality (Wahlsten and Bishop, unpublished observations). The I/LnJ strain shows extremely variable $\mathrm{HC}$ but has several other abnormalities that render interpretation difficult. A recent discovery of a new inbred strain with no CC and severely reduced HC (Wahlsten, unpublished data) should aid the search for gene identity and the analysis of physiological mechanisms of LTP and memory.

Some consideration of the human literature is needed to place our findings in a broader functional framework. Splitbrain patients tend to have minimal cognitive dysfunction associated with transection of the CC. Indeed, split-brain surgery results in a surprising lack of severe memory dysfunction in humans, and it produces no significant behavioral changes in monkeys (Springer and Deutsch, 1993). Patients with transection of the CC generally exhibit normal memory function (for review, see Clark and Geffen, 1989; Phelps et al., 1991), although Finlay et al. (2000) suggest that such patients may display some minor, but specific, cognitive deficits. Impairments associated with split-brain surgery can include difficulties in facial recognition and solution of geometric problems, as well as interhemispheric competition (Springer and Deutsch, 1993). Split-brain patients may retain the ability to perform everyday tasks because of hemispheric specialization and also because each hemisphere remains functional. Patients with callosal agenesis also show relatively few cognitive deficits (Sauerwein et al., 1994), perhaps because they develop compensatory behavioral strategies to cope with the absence of interhemispheric communication (Springer and Deutsch, 1993).

A more detailed study of split-brain patients that analyzed the extent of callosal and commissural transection, as well as memory function, indicated that transection of the $\mathrm{HC}$ (in addition to the $\mathrm{CC}$ ) elicits more profound memory deficits than callosal transection per se (Phelps et al., 1991). Memory deficits in HC-transected patients are limited to specific types of memory, and these deficits seem to encompass complex aspects of memory function (Phelps et al., 1991; Zaidel, 1995). Interestingly, a patient with an astrocytoma spanning the hippocampal commissure displayed amnesia (Gillespie et al., 2000). Our present data are in agreement with these findings, in that basic fear conditioning remained intact in mice lacking an intact $\mathrm{HC}$, whereas contextual fear extinction was impaired.

The study of mice exhibiting agenesis of the CC and/or HC may provide exciting new animal models that may prove useful for the development of treatments for syndromes associated with reduced $\mathrm{CC}$ and/or HC size. For example, magnetic resonance imaging studies show that human patients with fetal alcohol syndrome display numerous brain abnormalities, including agenesis of the CC and HC (Bhatara et al., 2002). Rat studies have found that alcohol ingestion during pregnancy can reduce $\mathrm{HC}$ size (Livy and Elberger, 2001). Also, reduced CC size in children may be correlated with attention-deficit hyperactivity disorder (ADHD) and dyslexia (Hynd et al., 1991, 1995; Baumgardner et al., 1996). Magara et al. (2000) used hybrid crosses of the acallosal mouse strain $\mathrm{I} / \mathrm{LnJ}$ as a potential animal model of ADHD, and they found that acallosal mice were more active than control mice and exhibited greater variability in activity than controls. However, it is unlikely that general activity levels influenced the results of our present study. Freezing levels of 9XCA/Wah and BALB/cWah1 were not significantly different during initial placement into the training environment (Fig. $3 A$, Pre $C S$ ).

In summary, our findings indicate that the $\mathrm{HC}$ contributes importantly to the regulation of both hippocampal short-term (but not long-term) synaptic plasticity and the acquisition of contextual fear extinction in the mouse. Three novel conclusions arise from our results: (1) lack of associational-commissural fibers to hippocampal area CA3 alters selected properties of the hippocampal trisynaptic pathway, such as PPF in the SC pathway; (2) normal contextual fear conditioning can occur in the absence of an intact $\mathrm{HC}$ and is correlated with robust expression of LTP in the $\mathrm{SC}$ and $\mathrm{MF}$ pathways of mice exhibiting a reduced $\mathrm{HC}$; and (3) contextual fear extinction is impaired in mice with a reduced HC, despite normal expression of LTP in the SC and MF pathways. 


\section{REFERENCES}

Andersen P, Blackstad TW, Lömo T (1966) Location and identification of excitatory synapses on hippocampal pyramidal cells. Exp Brain Res $1: 236-248$

Baumgardner TL, Singer HS, Denckla MB, Rubin MA, Abrams MT, Colli MJ, Reiss AL (1996) Corpus callosum morphology in children with Tourette syndrome and attention deficit hyperactivity disorder. Neurology 47:477-482.

Berman DE, Dudai Y (2001) Memory extinction, learning anew, and learning the new: dissociations in the molecular machinery of learning in cortex. Science 291:2417-2419.

Bhatara VS, Lovrein F, Kirkeby J, Swayze II V, Unruh E, Johnson V (2002) Brain function in fetal alcohol syndrome assessed by single photon emission computed tomography. S D J Med 55:59-62.

Blair HT, Schafe GE, Bauer EP, Rodrigues SM, LeDoux JE (2001) Synaptic plasticity in the lateral amygdala: a cellular hypothesis of fear conditioning. Learn Mem 8:229-242.

Bliss TV, Collingridge GL (1993) A synaptic model of memory: longterm potentiation in the hippocampus. Nature 361:31-39.

Bliss TV, Lömo T (1973) Long-lasting potentiation of synaptic transmission in the dentate area of the anaesthetized rabbit following stimulation of the perforant path. J Physiol (Lond) 232:331-356.

Bouton ME (1993) Context, time, and memory retrieval in the interference paradigms of Pavlovian learning. Psychol Bull 114:80-99.

Brun VH, Ytterbo K, Morris RG, Moser MB, Moser EI (2001) Retrograde amnesia for spatial memory induced by NMDA receptormediated long-term potentiation. J Neurosci 21:356-362.

Bulman-Fleming B, Wainwright PE, Collins RL (1992) The effects of early experience on callosal development and functional lateralization in pigmented BALB/c mice. Behav Brain Res 50:31-42.

Chen C, Kim JJ, Thompson RF, Tonegawa S (1996) Hippocampal lesions impair contextual fear conditioning in two strains of mice. Behav Neurosci 110:1177-1180.

Clark CR, Geffen GM (1989) Corpus callosum surgery and recent memory: a review. Brain 112:165-175.

Clugnet M, LeDoux JE (1990) Synaptic plasticity in fear conditioning circuits: induction of LTP in the lateral nucleus of the amygdala by stimulation of the medial geniculate body. J Neurosci 10:2818-2824.

Cook MN, Bolivar VJ, McFayden MP, Flaherty L (2002) Behavioral differences among 129 substrains: implications for knockout and transgenic mice. Behav Neurosci 116:600-611.

Fanselow MS, Kim JJ (1994) Acquisition of contextual Pavlovian fear conditioning is blocked by application of an NMDA receptor antagonist D,L-2-amino-5-phosphonovaleric acid to the basolateral amygdala. Behav Neurosci 108:210-212.

Fanselow MS, Kim JJ, Yipp J, De Oca B (1994) Differential effects of the $N$-methyl-D-aspartate antagonist DL-2-amino-5-phosphonovalerate on acquisition of fear of auditory and contextual cues. Behav Neurosci 108:235-240.

Finlay DC, Peto T, Payling J, Hunter M, Fulham WR, Wilkinson I (2000) A study of three cases of familial related agenesis of the corpus callosum. J Clin Exp Neuropsychol 22:731-742.

Flood JF, Jarvik ME, Bennett EL, Orme AE, Rosenzweig MR (1977) Protein synthesis inhibition and memory for pole jump active avoidance and extinction. Pharmacol Biochem Behav 7:71-77.

Fox GD, Holland PC (1998) Neurotoxic hippocampal lesions fail to impair reinstatement of an appetitively conditioned response. Behav Neurosci 112:255-260.

Frohardt RS, Guarraci FA, Bouton ME (2000) The effects of neurotoxic hippocampal lesions on two effects of context after fear extinction. Behav Neurosci 114:227-240.

Gillespie JSJ, Craig JJ, McKinstry CS (2000) Bilateral astrocytoma involving the limbic system precipitating disabling amnesia and seizures. Seizure 9:301-303.

Harris EW, Cotman CW (1986) Long-term potentiation of guinea pig mossy fiber responses is not blocked by $N$-methyl-D-aspartate antagonists. Neurosci Lett 70:132-137.

Herry C, Garcia R (2002) Prefrontal cortex long-term potentiation, but not long-term depression, is associated with the maintenance of extinction of learned fear in mice. J Neurosci 2 2:577-583.

Huang YY, Nguyen PV, Abel T, Kandel ER (1996) Long-lasting forms of synaptic potentiation in the mammalian hippocampus. Learn Mem 3:74-85.

Hynd GW, Semrud-Clikeman M, Lorys AR, Novey ES, Eliopulos D, Lyytinen H (1991) Corpus callosum morphology in attention deficithyperactivity disorder: morphometric analysis of MRI. J Learn Disabil 24:141-146.

Hynd GW, Hall J, Novey ES, Eliopulos D, Black K, Gonzalez JJ, Edmonds JE, Riccio C, Cohen M (1995) Dyslexia and corpus callosum morphology. Arch Neurol 52:32-38.

Johnston D, Wu S (1995) Foundations of cellular neurophysiology, pp 432-434. Cambridge MA: MIT.
Katz B, Miledi R (1968) The role of calcium in neuromuscular facilitation. J Physiol (Lond) 195:481-492.

Kim JJ, Fanselow MS (1992) Modality-specific retrograde amnesia of fear. Science 256:675-677.

Kim JJ, Rison RA, Fanselow MS (1993) Effects of amygdala, hippocampus and periaqueductal gray lesions on short- and long-term contextual fear. Behav Neurosci 107:1093-1098.

Lee H, Kim JJ (1998) Amygdalal NMDA receptors are critical for new fear learning in previously fear-conditioned rats. J Neurosci 18:8444-8454

Livy DJ, Elberger AJ (2001) Effect of prenatal alcohol exposure on midsagittal commissure size in rats. Teratology 63:15-22.

Magara F, Ricceri L, Wolfer DP, Lipp HP (2000) The acallosal mouse strain I/LnJ: a putative model of ADHD? Neurosci Biobehav Rev 24:45-50.

Majkowski J (1967) Electrophysiological studies of learning in split brain cats. Electroencephalogr Clin Neurophysiol 23:521-531.

Manahan-Vaughan D, Braunewell K-H (1999) Novelty acquisition is associated with induction of hippocampal long-term depression. Proc Natl Acad Sci USA 96:8739-8744.

Martin SJ, Grimwood PD, Morris RG (2000) Synaptic plasticity and memory: an evaluation of the hypothesis. Annu Rev Neurosci 23:649-711.

McKernan MG, Shinnick-Gallagher P (1997) Fear conditioning induces a lasting potentiation of synaptic currents in vitro. Nature 390:607-611.

Moser EI, Krobert KA, Moser MB, Morris RG (1998) Impaired spatial learning after saturation of long-term potentiation. Science 281:2038-2042.

Nguyen PV, Abel T, Kandel ER, Bourtchouladze R (2000a) Straindependent differences in LTP and hippocampus-dependent memory in inbred mice. Learn Mem 7:170-179.

Nguyen PV, Duffy SN, Young JZ (2000b) Differential maintenance and frequency-dependent tuning of LTP at hippocampal synapses of specific strains of inbred mice. J Neurophysiol 84:2484-2493.

Nicoll RA, Malenka RC (1995) Contrasting properties of two forms of long-term potentiation in the hippocampus. Nature 377:115-118.

Pavlov I (1927) Conditioned reflexes. Oxford: Oxford UP.

Phelps EA, Hirst W, Gazzaniga MS (1991) Deficits in recall following partial and complete commissurotomy. Cereb Cortex 1:492-498.

Phillips RG, LeDoux JE (1992) Differential contribution of amygdala and hippocampus to cued and contextual fear conditioning. Behav Neurosci 106:274-285.

Quirk GJ, Russo GK, Barron JL, Lebron K (2000) The role of ventromedial prefrontal cortex in the recovery of extinguished fear. J Neurosci 2 0:6225-6231.

Rogan MT, LeDoux JE (1995) LTP is accompanied by commensurate enhancement of auditory-evoked responses in a fear conditioning circuit. Neuron 15:127-136.

Rogan MT, Staubli UV, LeDoux JE (1997) Fear conditioning induces associative long-term potentiation in the amygdala. Nature 390:604-607.

Santini E, Muller RU, Quirk GJ (2001) Consolidation of extinction learning involves transfer from NMDA-independent to NMDAdependent memory. J Neurosci 21:9009-9017.

Sauerwein HC, Nolin P, Lassonde M (1994) Cognitive functioning in callosal agenesis. In: Callosal agenesis: the natural split brain (Lassonde M, Jeeves MA, eds), pp 221-234. New York: Plenum.

Schafe GE, Nader K, Blair HT, LeDoux JE (2001) Memory consolidation of Pavlovian fear conditioning: a cellular and molecular perspective. Trends Neurosci 24:540-546.

Schmidt SL, Manhães AC, de Moraes VZ (1991) The effects of total and partial callosal agenesis on the development of paw preference performance in the BALB/cCF mouse. Brain Res 545:123-130.

Schmued LC (1990) A rapid, sensitive histochemical stain for myelin in frozen brain sections. J Histochem Cytochem 38:717-720.

Scoville WB, Milner B (1957) Loss of recent memory after bilateral hippocampal lesions. J Neurol Neurosurg Psychiat 20:11-21.

Springer SP, Deutsch G (1993) Left brain, right brain, Ed 4, pp 29-63. New York: Freeman.

Tsien JZ, Huerta PT, Tonegawa S (1996) The essential role of hippocampal CA1 NMDA receptor-dependent synaptic plasticity in spatial memory. Cell 87:1327-1338.

Tzounopoulos T, Janz R, Sudhof TC, Nicoll RA, Malenka RC (1998) A role for cAMP in long-term depression at hippocampal mossy fiber synapses. Neuron 21:837-845.

Vianna MR, Szapiro G, McGaugh JL, Medina JH, Izquierdo I (2001) Retrieval of memory for fear-motivated training initiates extinction requiring protein synthesis in the rat hippocampus. Proc Natl Acad Sci USA 98:12251-12254

Wahlsten D (1989) Deficiency of the corpus callosum: incomplete penetrance and substrain differentiation in BALB/c mice. J Neurogenet 5:61-76. 
Wahlsten D, Sparks V (1995) New recombinant inbred strains expressing $100 \%$ total absence of the corpus callosum. Soc Neurosci Abstr 21:796.

Wahlsten D, Crabbe JC, Dudek BC (2001) Behavioural testing of standard inbred and 5HT(1B) knockout mice: implications of absent corpus callosum. Behav Brain Res 125:23-32.

Walker DL, Davis M (2002) The role of amygdala glutamate receptors in fear learning, fear-potentiated startle, and extinction. Pharmacol Biochem Behav 71:379-392.

Wilson A, Brooks DC, Bouton ME (1995) The role of the rat hippocampal system in several effects of context in extinction. Behav Neurosci 109:828-836

Woo NH, Duffy SN, Abel T, Nguyen PV (2000) Genetic and pharma- cological demonstration of differential recruitment of cAMPdependent protein kinases by synaptic activity. J Neurophysiol 84:2739-2745.

Zaidel DW (1995) The case for a relationship between human memory, hippocampus and corpus callosum. Bio Res 28:51-57.

Zaidel DW, Sperry RW (1974) Memory impairment after commissurotomy in man. Brain 97:263-272.

Zalutsky RA, Nicoll RA (1990) Comparison of two forms of long-term potentiation in single hippocampal neurons. Science 248:1619-1624.

Zola-Morgan S, Squire LR, Amaral DG (1986) Human amnesia and the medial temporal region: enduring memory impairment following a bilateral lesion limited to field CA1 of the hippocampus. J Neurosci 6:2950-2967. 